\title{
Predicting the Unknown and the Unknowable. Are Anthropometric Measures and Fitness Profile Associated with the Outcome of a Simulated CrossFit ${ }^{\circledR}$ Competition?
}

\author{
Javier Peña ${ }^{1,2,3,+}+\mathbb{D}$, Daniel Moreno-Doutres ${ }^{3, *},+(\mathbb{D})$, Iván Peña ${ }^{3}$, Iván Chulvi-Medrano $4 \mathbb{D}^{\mathbb{D}}$, Alberto Ortegón ${ }^{5}$, \\ Joan Aguilera-Castells 5 (iD) and Bernat Buscà ${ }^{5}$ (D)
}

1 Sport and Physical Activity Studies Centre (CEEAF), University of Vic-Central University of Catalonia, 08500 Vic, Spain; javier.pena@uvic.cat

2 Sport Performance Analysis Research Group (SPARG), University of Vic-Central University of Catalonia 08500 Vic, Spain

3 ICON Training S.L., 08912 Barcelona, Spain; ivanpenalopez4@gmail.com

4 Sport Performance and Physical Fitness Research Group (UIRFIDE), Department of Physical and Sports Education, Faculty of Physical Activity and Sports Sciences, University of Valencia, 46010 Valencia, Spain; ivan.chulvi@uv.es

5 Department of Sports Sciences, Ramon Llull University, FPCEE Blanquerna, 08022 Barcelona, Spain; a.ortegon@outlook.es (A.O.); joanac1@blanquerna.url.edu (J.A.-C.); BernatBS@blanquerna.url.edu (B.B.)

* Correspondence: dani.moreno@dmtrainingpro.com

+ Co-first author, these authors contributed equally to this work.

check for updates

Citation: Peña, J.; Moreno-Doutres, D.; Peña, I.; Chulvi-Medrano, I.; Ortegón, A.; Aguilera-Castells, J.; Buscà, B. Predicting the Unknown and the Unknowable. Are Anthropometric Measures and Fitness Profile Associated with the Outcome of a Simulated CrossFit ${ }^{\circledR}$ Competition?. Int. J. Environ. Res. Public Health 2021, 18, 3692. https:// doi.org/10.3390/ijerph18073692

Received: 23 February 2021

Accepted: 29 March 2021

Published: 1 April 2021

Publisher's Note: MDPI stays neutral with regard to jurisdictional claims in published maps and institutional affiliations.

Copyright: (c) 2021 by the authors. Licensee MDPI, Basel, Switzerland. This article is an open access article distributed under the terms and conditions of the Creative Commons Attribution (CC BY) license (https:/ / creativecommons.org/licenses/by/ $4.0 /)$.

\begin{abstract}
The main objective of this research was to find associations between the outcome of a simulated CrossFit ${ }^{\circledR}$ competition, anthropometric measures, and standardized fitness tests. Ten experienced male CrossFit ${ }^{\circledR}$ athletes (age $28.8 \pm 3.5$ years; height $175 \pm 10.0 \mathrm{~cm}$; weight $80.3 \pm 12.5 \mathrm{~kg}$ ) participated in a simulated CrossFit ${ }^{\circledR}$ competition with three benchmark workouts ("Fran", "Isabel", and "Kelly") and underwent fitness tests. Participants were tested for anthropometric measures, sit and reach, squat jump (SJ), countermovement jump (CMJ), and Reactive Strength Index (RSI), and the load (LOAD) corresponding to the highest mean power value (POWER) in the snatch, bench press, and back squat exercises was determined using incremental tests. A bivariate correlation test and k-means cluster analysis to group individuals as either high-performance (HI) or low performance (LO) via Principal Component Analysis (PCA) were carried out. Pearson's correlation coefficient two-tailed test showed that the only variable correlated with the final score was the snatch LOAD $(p<0.05)$. Six performance variables (SJ, CMJ, RSI, snatch LOAD, bench press LOAD, and back squat LOAD) explained $74.72 \%$ of the variance in a $\mathrm{k}=2$ means cluster model. When CrossFit ${ }^{\circledR}$ performance groups $\mathrm{HI}$ and LO were compared to each other, $t$-test revealed no difference at a $p \leq 0.05$ level. Snatch maximum power LOAD and the combination of six physical fitness tests partially explained the outcome of a simulated CrossFit competition. Coaches and practitioners can use these findings to achieve a better fit of the practices and workouts designed for their athletes.
\end{abstract}

Keywords: performance; athlete; high-intensity functional training; cross-training; functional fitness

\section{Introduction}

CrossFit ${ }^{\circledR}$ is a training method property of CrossFit ${ }^{\circledR}$ Inc. (Washington, DC, USA), a company established in 2000 by Greg Glassman and Laura Jenai. This form of physical exercise incorporates elements from other disciplines, such as weightlifting, powerlifting, gymnastics, calisthenics, and strength athletics, while following high-intensity exercise principles and using constant variability as one of its core elements. According to data from the company, the number of official CrossFit ${ }^{\circledR}$ affiliated gyms in the world is close to 15,000 [1], a figure that shows the worldwide interest in this exercise regime. Apart from the CrossFit ${ }^{\circledR}$ activity aimed at the general population, CrossFit ${ }^{\circledR}$ Inc. has developed a 
competitive trend that also enjoys considerable international popularity. In 2019, 144,276 people completed all the workouts of the day (WODs) of the CrossFit Open ${ }^{\circledR}$ as prescribed or "RX" [2] (meaning that the athletes used the prescriptive weight or height, completed the prescribed number of repetitions, and followed the full standards for each movement). Alongside 15 sanctioned events, the CrossFit Open ${ }^{\circledR}$ is the only way to qualify for the CrossFit Games ${ }^{\circledR}$, where the elite of this sport has convened every year since 2007.

Adult $\mathrm{CrossFit}^{\circledR}$ participation seems to entail similar physical demands (in terms of $\mathrm{VO}_{2}$ max, muscle size, strength and endurance gains) to other high-intensity physical activities [3]. Several cohort studies have reported improvements in $\mathrm{VO}_{2}$ max [4,5], body composition [6,7], and specific work capacity [8] in men and women in interventions ranging from 6 to 10 weeks. Thus, CrossFit ${ }^{\circledR}$ WODs are a demanding form of exercise, and physiologically, both aerobic and anaerobic metabolisms influence the athlete's performance [9].

General strength improvements associated with $\mathrm{CrossFit}^{\circledR}$ participation are also described in the literature with conflicting results. Significant increases in several muscular strength and endurance tests after participation in CrossFit ${ }^{\circledR}$ workouts have been reported in some studies [5], while in some others, no significant differences were noted postintervention [8].

However, all the studies mentioned above have two critical limitations highlighted in systematic reviews: a reduced number of scientific studies because the discipline is still incipient, and a lack of a high level of evidence at low risk of bias [10].

To date, several studies have highlighted that the physical stress caused by CrossFit ${ }^{\circledR}$ WODs is comparable to a 20 min high-intensity treadmill run at $90 \%$ of maximal heart rate [11] and superior to an ACSM-based training session in terms of fatigue, muscle soreness, and muscle swelling [12]. Rating of perceived exertion (RPE) seems consistently high after CrossFit ${ }^{\circledR}$ routines [12,13], and increased lactate [13-15] and pro/anti-inflammatory cytokine production [14] is also present in several scientific reports assessing these activities.

Although CrossFit ${ }^{\circledR}$ athletic competitions generate significant revenues, not many previous studies have dealt with competitive performance factors. Numerous scientific contributions have investigated the epidemiology of CrossFit ${ }^{\circledR}[3,16-18]$, with several cases of spinal injuries [19] and rhabdomyolysis [20] reported, but not many pieces of research have provided insight about the relevant elements of fitness to succeed in competitions. For instance, a study comparing the outcomes in three benchmark WODs- "Grace" (30 clean and jerks for time), "Fran" (three rounds of thrusters and pull-ups for 21, 15, and 9 repetitions), and "Cindy" (20 min of rounds of 5 pull-ups, 10 push-ups, and 15 bodyweight squats) - found that whole-body strength and anaerobic threshold exhibited association with specific $\mathrm{CrossFit}^{\circledR}$ performance [21]. In a similar analysis with 32 healthy adult males, age, group (experienced vs. inexperienced), $\mathrm{VO}_{2}$ max, and anaerobic power were predictors of a $12 \mathrm{~min}$ as many repetitions as possible WOD with 12 throws of a $9.07 \mathrm{~kg}$ medicine ball at a $3.05 \mathrm{~m}$ target, 12 swings of a $16.38 \mathrm{~kg}$ kettlebell, and 12 burpee pull-ups [22]. In the same article, only CrossFit ${ }^{\circledR}$ experience was a significant predictor in a WOD with sumo deadlift high pull, a $0.5 \mathrm{~m}$ box jump, and a $40 \mathrm{~m}$ farmer's walk with $40 \mathrm{~kg}$ following a three-round with 21, 15, and 9 repetitions per exercise structure. Recent research has also found that absolute $\mathrm{VO}_{2}$ peak values and CrossFit ${ }^{\circledR}$ Total (one repetition maximum tests for the back squat, deadlift, and overhead press) were predictors of the 19.1 CrossFit Open ${ }^{\circledR}$ workout and the benchmark "Fran" performances, respectively [23]. Body composition was revealed as the most significant success predictor in the 2018 CrossFit Open ${ }^{\circledR}[24]$.

Despite an increased number of scientific studies due to the growth in popularity of CrossFit ${ }^{\circledR}$, there is still an important space for further research about CrossFit ${ }^{\circledR}$ athletic competitions. The main objective of this cross-sectional study was to find associations between the outcome of a simulated CrossFit ${ }^{\circledR}$ competition, anthropometric measures, and standardized fitness tests, providing insight to coaches and athletes to achieve better competitive performance. 


\section{Materials and Methods}

\subsection{Participants}

A purposive sample of ten experienced male CrossFit ${ }^{\circledR}$ athletes (age $28.8 \pm 3.5$ years; height $175 \pm 10.0 \mathrm{~cm}$; weight $80.3 \pm 12.5 \mathrm{~kg}$; one-hand reach $223 \pm 15 \mathrm{~cm}$ ) without relevant injuries at the moment of the study and recruited from official CrossFit ${ }^{\circledR}$ affiliates volunteered to participate in the study. The inclusion criteria were set based on weekly training volume ( $\geq 5$ sessions / week), competitive CrossFit ${ }^{\circledR}$ background ( $\geq 2$ years), regular participation in regional $(n=1)$, national $(n=5)$, or international $(n=4)$ competitions, and their ability to perform the $R X$ versions of the workouts (respecting the metabolic purpose of the WOD and being able to lift the weights without fatal technical flaws in the presence of fatigue). Before starting the study, we informed the participants about the experimental procedures and they signed informed consent and provided additional data by filling out a modified Physical Activity Readiness Questionnaire (PAR-Q) [25]. Procedures followed the Declaration of Helsinki and its later amendments [26] and were approved by the Research Ethics Committee of the University of Vic - Central University of Catalonia in Barcelona, Spain (ref. no. 46/2018).

\subsection{Experimental Procedures}

Testing was conducted over two separate sessions. In the first session, before starting a simulated $\mathrm{CrossFit}^{\circledR}$ competition, we tested the participants for anthropometric measures and a sit-and-reach flexibility test. Weight was assessed on an electronic scale (PS160, Beurer, Germany) with an accuracy of $\pm 0.1 \mathrm{~kg}$. Height was measured using a roll-up measuring tape with wall attachment (206, Seca ${ }^{\circledR}$, Hamburg, Germany) with an accuracy of $\pm 0.01 \mathrm{~m}$. One-hand reach was assessed using a measuring tape (TM-CO2, Tacklife, New York, NY, USA). Body fat percentages were calculated using the equation of Jackson and Pollock [27] measuring the skinfold thickness at three sites (chest, abdomen, and thigh) using a caliper (Holtain Ltd. Tanner/Whitehouse Skinfold Caliper, Holtain, Dyfed, UK). One experienced anthropometrist carried out all the tests following the protocols established by the International Society for the Advancement of Kinanthropometry (ISAK). The sit-and-reach test was performed twice using a sit-and-reach box (Sit and Reach testing box, Eveque, Northwich, UK) and considering the best score as the final result in the test. Later, all of the participants completed three benchmark WODs in random order with a 30 min rest in between them, simulating a CrossFit ${ }^{\circledR}$ Competition. The three selected WODs were "Fran", "Isabel", and "Kelly", and they were performed in that same order (Table 1). These WODs were selected because they are popular benchmark WODs in the CrossFit $^{\circledR}$ community and because they incorporate very diverse skills and fitness elements (Olympic lifting movements, calisthenics, pure conditioning movements, and exercises with high $\mathrm{VO}_{2}$ max demands).

Table 1. Workouts performed in the simulated CrossFit ${ }^{\circledR}$ competition.

\begin{tabular}{ccc}
\hline WOD 1 “FRAN" & WOD 2 “ISABEL” & WOD 3 “KELLY” \\
\hline & & Five rounds as fast as possible \\
21-15-9 Repetitions of & of $400 \mathrm{~m}$ run, 30 box jumps \\
thrusters (42.5 kg) and & Repetitions of snatch $(60$ & $(0.5$ meters $)$, and 30 wall balls \\
pull-ups as fast as possible. & kg) as fast as possible. & $(9.07 \mathrm{~kg}$ medicine ball at a \\
& & $3.05 \mathrm{~m}$ target). \\
\hline
\end{tabular}

Every participant was assigned a certified CrossFit ${ }^{\circledR}$ judge to control their performance, and the WODs were completed in two series or "heats". Participants for the two heats in the first WOD were selected at random, while for the second and third WODs, the athletes with better accumulated scores were assigned to the second heat reproducing the usual CrossFit ${ }^{\circledR}$ competition procedures. During the second session, a week later, we carried out the rest of the measurements (Table 2). Squat jump (SJ), countermovement jump (CMJ), and a $0.7 \mathrm{~m}$ drop jump (DJ) were measured using a contact mat (Ergojump-Plus, Ergotest 
Innovation, Norway) consisting of a switch mat connected to a digital timer (with an accuracy of $\pm 0.001 \mathrm{~s}$ ). Contact time and resulting height in the DJ were used to calculate Reactive Strength Index (RSI) by using the formula: RSI = Jump Height $(\mathrm{cm}) /$ Ground Contact Time (ms). All of the jumps were performed three times, and the best score was the final result in the tests. The loads (LOAD) corresponding to the highest mean power value (POWER) in the snatch, bench press, and back squat exercises were determined using incremental tests $[28,29]$ and were measured with a linear encoder (MuscleLabTM, Ergotest Innovation, Stathelle, Norway) attached to the barbell. To assess the ability of the athletes to perform intermittent efforts, a Yo-Yo intermittent recovery test 2 (IR-2) was administered, and the distance covered was used to calculate $\mathrm{VO}_{2}$ max $(\mathrm{mL} / \mathrm{min} / \mathrm{kg})$ using the formula: IR-2 distance $(\mathrm{m}) \times 0.0136+45.3$ [30]. All the mentioned tests were chosen because they show ecological and construct validity, the movements used are very similar to those of $\mathrm{CrossFit}^{\circledR}$, and the tests enabling calculations have been validated by previous scientific literature.

Table 2. Protocols followed in the incremental tests.

\begin{tabular}{ccc}
\hline SNATCH & BENCH PRESS & BACK SQUAT \\
\hline $\begin{array}{c}\text { First load was set at the 65\% of } \\
\text { the one-repetition maximum } \\
(1 \mathrm{RM}) \text { in the movement with } \\
5 \% \text { increments until failure. }\end{array}$ & $\begin{array}{c}\text { Concentric execution of the } \\
\text { exercise with } 4 \text { different loads } \\
\text { ranging between } 30 \text { and } 80 \% \\
\text { of the one-repetition } \\
\text { maximum (1RM) in the } \\
\text { movement. }\end{array}$ & $\begin{array}{c}\text { Concentric execution of the } \\
\text { exercise with } 4 \text { different loads } \\
\text { ranging between } 30 \text { and } 80 \% \\
\text { of the one-repetition } \\
\text { maximum (1RM) in the } \\
\text { movement. }\end{array}$ \\
\hline $\begin{array}{c}\text { Participants performed 2 } \\
\text { repetitions at any given load } \\
\text { with 10 s of rest between } \\
\text { attempts and a 3 min rest } \\
\text { between loads. }\end{array}$ & $\begin{array}{c}\text { Participants performed 2 } \\
\text { repetitions at any given load } \\
\text { with 10 s of rest between } \\
\text { attempts and a 3 min rest } \\
\text { between loads. }\end{array}$ & $\begin{array}{c}\text { Participants performed 2 } \\
\text { repetitions at any given load } \\
\text { with 10 s of rest between } \\
\text { attempts and a 3 min rest } \\
\text { between loads. }\end{array}$ \\
\hline
\end{tabular}

\subsection{Statistical Analysis}

Using a statistical package (SPSS 21 for macOS, SPSS Inc, Chicago, IL, USA), a ShapiroWilk test was used to determine if the sample data was normally distributed prior to conducting a bivariate correlation test between the final competition score-assigning 10 points to the best-ranked competitor in each WOD, 9 to the next one, and consecutively so until the last competitor-and the different physical condition tests conducted in the study. Significance level was established at $p<0.05(\alpha=5 \%)$ with a 95\% confidence interval. In the second term, $\mathrm{R}$, a language and environment for statistical computing (R 3.5.1 GUI 1.70 for macOS, R Foundation for Statistical Computing, Vienna, Austria), was used to normalize physical tests, centering them at 0 to avoid between-variable scale differences, carrying out a k-means cluster $(\mathrm{k}=2)$ analysis considering the outcome of the physical tests to group individuals as either high (HI) or low (LO) performance. Later, a t-test was used to compare composite WOD scores between HI and LO groups. Finally, a Principal Component Analysis (PCA) was carried out to determine the influence of each physical test on the simulated CrossFit ${ }^{\circledR}$ competition final composite score.

\section{Results}

The Shapiro-Wilk test showed that the variables included in the analysis were normally distributed ( $p>0.05)$. A bivariate Pearson's correlation coefficient two-tailed test of significance showed that the only variable showing a very large correlation [31] with the final score of the competition was the snatch LOAD $(p<0.05)$; none of the other variables showed association with the competition outcome (Table 3). Although weekly volume of training was not significantly correlated with the final competition score $(p=0.142)$, the r-value showed a promising correlation (0.50) with this factor. 
Table 3. Correlation coefficients, interpretation, and significance levels in the variables included in the study.

\begin{tabular}{ccc}
\hline Variables & $\begin{array}{c}\text { Correlation } \\
\text { (r and Interpretation) }\end{array}$ & Significance $(p$-Value) \\
\hline Age $(\mathrm{y})$ & -0.36, moderate & 0.300 \\
\hline Weight $(\mathrm{kg})$ & 0.12, small & 0.736 \\
\hline Height $(\mathrm{cm})$ & 0.25, small & 0.490 \\
\hline Reach $(\mathrm{cm})$ & 0.21, small & 0.566 \\
\hline Hours of training per week $(\mathrm{h})$ & 0.50, large & 0.142 \\
\hline Body fat $\%$ & 0.06, trivial & 0.874 \\
\hline Sit and reach $(\mathrm{cm})$ & 0.05, trivial & 0.896 \\
\hline Squat jumpJ $(\mathrm{cm})$ & 0.27, small & 0.452 \\
\hline Countermovement jump $(\mathrm{cm})$ & 0.31, medium & 0.390 \\
\hline Reactive strength index & 0.14, small & 0.695 \\
\hline Snatch LOAD $(\mathrm{kg})$ & 0.74, very large & $0.014 *$ \\
\hline Snatch POWER $(\mathrm{W})$ & -0.13, small & 0.721 \\
\hline Bench press LOAD $(\mathrm{kg})$ & 0.32, moderate & 0.368 \\
\hline Bench press POWER $(\mathrm{W})$ & 0.34, moderate & 0.337 \\
\hline Back squat LOAD $(\mathrm{kg})$ & 0.30, moderate & 0.392 \\
\hline Back squat POWER $(\mathrm{W})$ & 0.2, trivial & 0.548 \\
\hline Yo-Yo test IR-2 $(\mathrm{m})$ & 0.40, moderate & 0.253 \\
\hline Den $)$ & & \\
\hline
\end{tabular}

${ }^{*}$ Denotes significant correlation $(p<0.05)$.

A k-means model established two centroids that determined the two groups, $\mathrm{HI}(n=6)$ and LO $(n=4)$ (Figure 1). The unpaired $t$-test comparison revealed no differences between $\mathrm{HI}$ and LO groups in WOD scores.

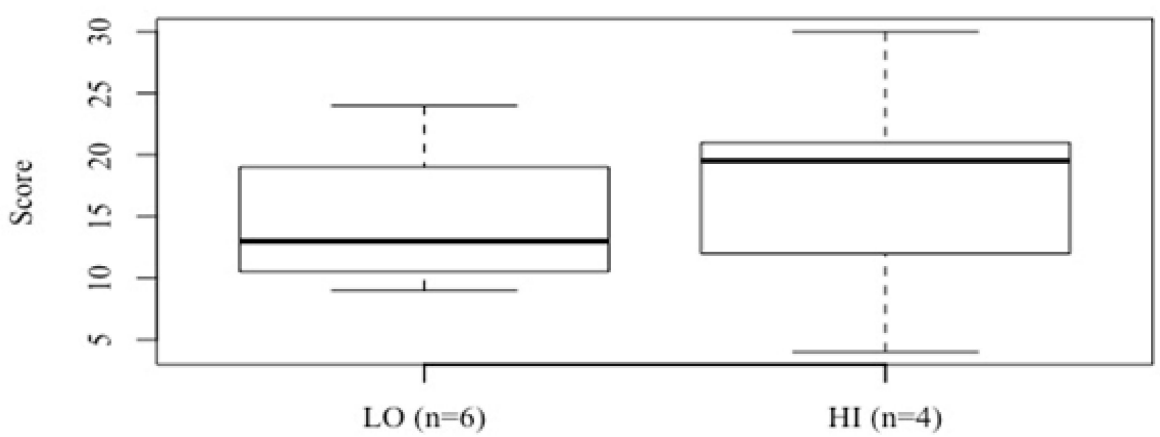

Groups

Figure 1. Boxplot visualization of the k-means cluster analysis grouping individuals as either highperformance (HI) or low performance (LO) and showing the minimum score, first quartile, median, third quartile, and maximum score achieved in the simulated competition by every group.

PCA cluster explains $74.72 \%$ of the variance using six performance variables measured in the study (SJ, CMJ, RSI, snatch LOAD, bench press LOAD, and back squat LOAD) (Figure 2). When CrossFit ${ }^{\circledR}$ performance groups $\mathrm{HI}$ and LO were compared, the $t$-test revealed no difference at $p \leq 0.05$ level. 


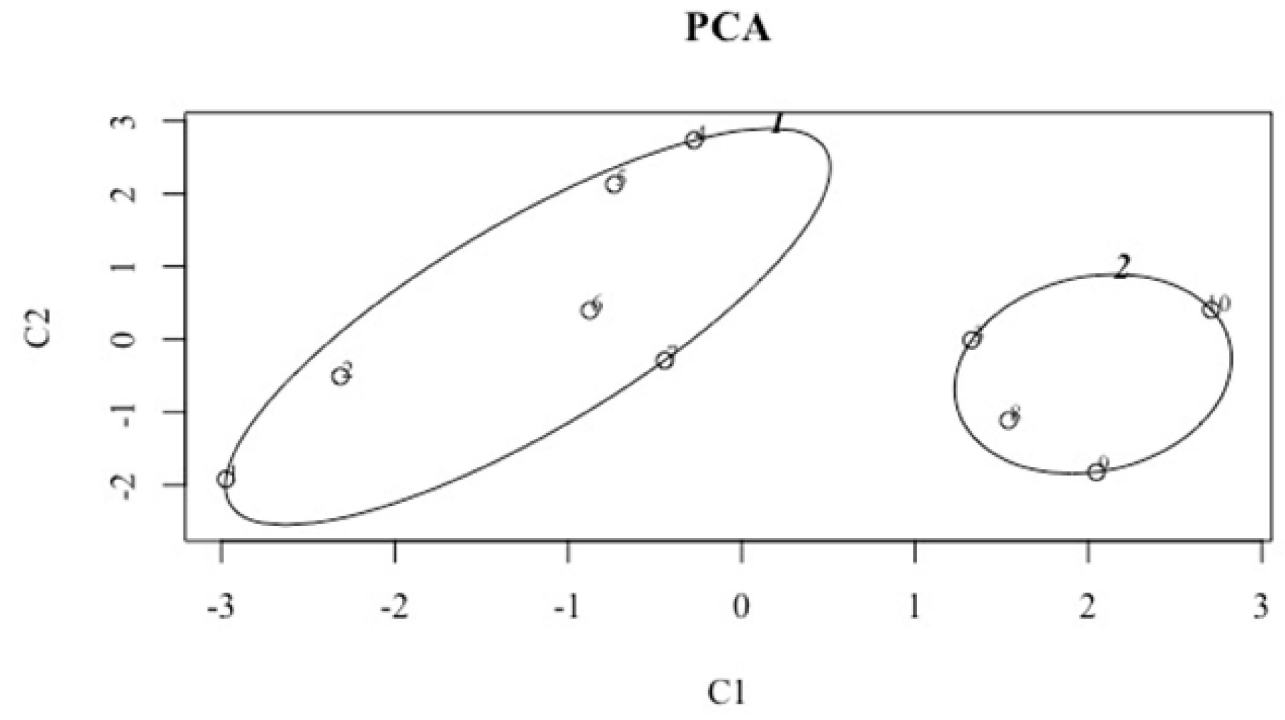

Figure 2. Principal Component Analysis with concentration and confidence ellipses around each group, including the six performance measures. Each main component is obtained by linear combination of the original six variables, and every dot inside the ellipses represents one individual in the $\mathrm{HI}(n=6)$ and $\mathrm{LO}(n=4)$ groups. These two components explain $74.72 \%$ of the point variability.

The average values obtained in the tests included in the PCA are presented to describe the performances obtained by the athletes who participated in our study (Table 4).

Table 4. Average values obtained in the tests included in the PCA.

\begin{tabular}{ccccccc}
\hline $\begin{array}{c}\text { Descriptive } \\
\text { Statistics }\end{array}$ & SJ (cm) & $\begin{array}{c}\text { CMJ } \\
(\mathbf{c m})\end{array}$ & RSI & $\begin{array}{c}\text { Snatch } \\
\text { LOAD (kg) }\end{array}$ & $\begin{array}{c}\text { Bench Press } \\
\text { LOAD (kg) }\end{array}$ & $\begin{array}{c}\text { Squat } \\
\text { LOAD (kg) }\end{array}$ \\
\hline Mean & 33.1 & 38.1 & 0.114 & 59.6 & 53.8 & 65.7 \\
\hline $\begin{array}{c}\text { Standard } \\
\text { deviation }\end{array}$ & 8.7 & 7.2 & 0.033 & 9.7 & 14.8 & 21.6 \\
\hline
\end{tabular}

\section{Discussion}

The purpose of this study was to determine if a battery of standardized physical fitness tests can predict the outcome of a simulated $\mathrm{CrossFit}^{\circledR}$ competition. Competitive CrossFit ${ }^{\circledR}$ is a complex discipline, where many different skills and elements of physical fitness (endurance, stamina, strength, flexibility, power, speed, coordination, agility, balance, and accuracy) come into play to achieve success. Due to this complexity, the CrossFit ${ }^{\circledR}$ community has always accepted that the best way to assess performance (and therefore fitness levels) is to perform CrossFit ${ }^{\circledR}$ benchmark WODs and participate in CrossFit ${ }^{\circledR}$ competitions. This approach has significant limitations; specific CrossFit ${ }^{\circledR}$ workouts test more than one capacity, making it difficult to attribute the progress in a workout to all of them equally. If we improve our time or repetitions in one particular CrossFit ${ }^{\circledR}$ benchmark WOD, it is unfeasible to know if strength, skill, or conditioning was the main explanatory factor of this enhancement in performance. Additionally, CrossFit ${ }^{\circledR}$ competitive performance requires psychological and physiological settings. Thus, understanding the attributes related with CrossFit ${ }^{\circledR}$ performance can be relevant for two main reasons: it can be helpful to predict individual competitive outcomes and to work on the athletes' weaknesses, improving their performances.

Previous research has suggested a relationship between a combination of power measurements [22], whole-body strength [21], and power in the full-squat test [32], and CrossFit ${ }^{\circledR}$ performance. However, this approach has limitations. On the one hand, it is undeniable that benchmarks and competitions are specific; they reproduce the "unknown and unknow- 
able" axiom of the sport. Nevertheless, using them to test fitness can be time-consuming, and for some recreational athletes, the RX standards can be unachievable. In some WODs, this changes the "testing" conditions dramatically, because it is evident that it is not the same to perform the benchmark "Fran" with a $30 \mathrm{~kg}$ barbell and jumping pull-ups or to use the prescribed weight and movements in the RX version. Standardized tests are valid, reliable, accurate, and sensitive to detect changes in fitness, being useful in different populations and age groups. Their main disadvantage is the need for equipment that can be expensive and, in some cases, requires training to be used. However, their application is fast, and they equalize the execution conditions for everyone.

The data reported in the present study partially support the initial hypothesis. Only the result of one incremental test, the snatch, showed a strong (but not perfect) correlation with the outcome of the competition, and this was more than likely conditioned by the fact that one of the benchmark WODs in the event ("Isabel") depended exclusively on the ability to perform this movement repeatedly with a high requirement of power. Despite this, the battery used in our study could discriminate between high (HI) and (low) LO performance athletes in the sample, explaining $74.72 \%$ of the variance with six performance variables measured. This result is consistent with that of other researchers arguing that $\mathrm{CrossFit}^{\circledR}$ experience and training level is a critical component of performance in CrossFit ${ }^{\circledR}$ workouts [22]. Weekly volume of training was not significantly correlated with the final competition score in our data, but a large correlation value (0.50) indicates that this factor can be considered as relevant in future research.

The lack of association between the individual outcome of the different fitness tests proposed and the simulated competition can be solved using a battery of tests. In one of the few investigations that we know regarding this matter, it was found that it is unfeasible to pretend that a single test of any nature can predict the result of a benchmark WOD in CrossFit ${ }^{\circledR}$ [21].

Although the benchmark WODs in this study were selected because they present very different physical condition elements (aerobic and anaerobic demands, weightlifting, gymnastics, and conditioning movements), the variables that could explain the variance were all of a similar nature; the only test assessing $\mathrm{VO}_{2}$ max in our design showed no predictive power. "Fran" and "Isabel" are WODs that elite and sub-elite athletes can finish in less than five minutes, and "Kelly" lasts no longer than $20 \mathrm{~min}$ in these populations. This data agrees with previous research, where $\mathrm{VO}_{2}$ max did not predict CrossFit ${ }^{\circledR}$ performance [21]. However, $\mathrm{VO}_{2}$ max has explained $68 \%$ of the variance in the outcome of the workout "Nancy" [33], with five rounds of $400 \mathrm{~m}$ run. In our case, the chosen workouts had an anaerobic predominance, and the rest periods between WODs were enough to emphasize the importance of muscular power in the competitive outcome, showing an enhanced specific work capacity in the athletes [8]. In this direction, a test using four consecutive Wingate anaerobic tests has predicted $\mathrm{CrossFit}^{\circledR}$ specific performance in previous investigations [34].

We did not find any relationship between anthropometric measures and CrossFit ${ }^{\circledR}$ specific performance. This may be attributed to the participants' characteristics as expert athletes with suitable body composition (body fat $8.2 \pm 2.83 \%$ ) for their competitive development. The intrinsic characteristics of advanced $\mathrm{CrossFit}^{\circledR}$ athletes and the purposive sampling used in this research piece may have been a limiting factor in finding an association between body composition and competition outcome. All the athletes in our sample clearly showed a physical condition above the average among CrossFit ${ }^{\circledR}$ enthusiasts.

Flexibility levels were also shown not to be correlated with CrossFit ${ }^{\circledR}$ performance in our study. To the best of our knowledge, no previous research has included flexibility as a possible predictor of CrossFit ${ }^{\circledR}$ performance.

The present results should be interpreted with caution. The competition level of the athletes volunteering in our study (sub-elite) and the sample size are limitations to use our results to make inferences about other populations like elite athletes (CrossFit Games ${ }^{\circledR}$ caliber) or inexperienced CrossFit ${ }^{\circledR}$ recreational athletes. The selection of tests and 
benchmark WODs could also be a limitation. We should also understand that although all participants were instructed to perform all the WODs at the maximum intensity, the context (a simulated competition) could be less motivating than real competition settings.

Future work on the current topic is therefore recommended to apply these findings to different cohorts, using other benchmark WODs or workouts from a real competitive event. Incorporating different standardized tests that can lead to more robust results, and a higher percentage of the variance of the outcome explained by the selected performance factors, could also be desirable.

This study set out to know in greater depth what the critical elements of physical fitness are that allow one to achieve a good result in a simulated CrossFit ${ }^{\circledR}$ competition. The load at which the maximum snatch power was achieved and the combination of six physical fitness tests (SJ, CMJ, RSI, snatch LOAD, bench press LOAD, and back squat LOAD) partially explained the outcome of a simulated CrossFit ${ }^{\circledR}$ competition with the benchmarks "Fran", "Isabel", and "Kelly". Coaches and practitioners can use these findings to improve their decision-making processes and to use these tests as an element that can allow a better fit of the practices and workouts designed for their athletes.

\section{Conclusions}

Results coming from this article show that isolated physical condition tests can be misleading to explain the outcome of a CrossFit ${ }^{\circledR}$ WOD. These individual tests can only be useful in cases where the benchmark WODs performed in the CrossFit ${ }^{\circledR}$ context and its results are strongly related to the execution of one particular movement. Batteries of tests can help to discriminate athletes of different levels, showing that a better physical condition expressed in the battery is partially associated with a better overall performance in the specific CrossFit ${ }^{\circledR}$ activity. These batteries should implement tests that are valid, reliable, accurate, and sensitive to detect changes in fitness, but at the same time show some level of specificity with competitive CrossFit ${ }^{\circledR}$ requirements and CrossFit ${ }^{\circledR}$ athletes' specific needs.

Author Contributions: Conceptualization, J.P., D.M.-D., I.P. and A.O.; methodology, J.P., D.M.-D., I.P. and A.O.; formal analysis, J.P., D.M.-D., B.B. and J.A.-C.; data curation, J.P., D.M.-D., B.B., I.C.-M. and J.A.-C.; investigation, J.P., D.M.-D., I.P. and A.O.; writing-original draft preparation, J.P., D.M.-D., B.B. and I.C.-M.; writing-review and editing, J.P., D.M.-D., B.B. and I.C.-M.; project administration, J.P., I.P. and A.O. All authors have read and agreed to the published version of the manuscript.

Funding: This research received no external funding.

Institutional Review Board Statement: Ethical approval was given by the Research Ethics Committee of the University of Vic-Central University of Catalonia in Barcelona, Spain (ref. no. 46/2018).

Informed Consent Statement: Informed consent was obtained from all subjects involved in the study.

Data Availability Statement: The data that support the findings of this study are available on request from the corresponding author.

Acknowledgments: The authors would like to give explicit thanks to the athletes and judges that kindly volunteered in the study, as well as to the owners of the premises in which the study was carried out. We also would like to thank Amy Gibson for her assistance in the preparation of this article.

Conflicts of Interest: The authors declare no conflict of interest. CrossFit ${ }^{\circledR}$ is a registered trademark of CrossFit, Inc. and any use of the term in this article is adopted merely as nominative in nature. The authors are not endorsed or sponsored by CrossFit Inc. in any way.

\section{References}

1. CrossFit: About Affiliation. Available online: https://www.crossfit.com/affiliate (accessed on 19 March 2021).

2. How Many People Participated in the 2019 CrossFit Open? Available online: https://morningchalkup.com/2019/04/01/sohow-many-people-participated-in-the-2019-crossfit-open/ (accessed on 19 March 2021). 
3. Meyer, J.; Morrison, J.; Zuniga, J. The Benefits and Risks of CrossFit: A Systematic Review. Work. Health Saf. 2017, 65, 612-618. [CrossRef]

4. Smith, M.M.; Sommer, A.J.; Starkoff, B.E.; Devor, S.T. Crossfit-Based High-Intensity Power Training Improves Maximal Aerobic Fitness and Body Composition. J. Strength Cond. Res. 2013, 27, 3159-3172. [CrossRef] [PubMed]

5. Brisebois, M.F.; Castleberry, T.J.; Irvine, C.J.; Deemer, S.E.; Rigby, B.R. Physiological and Fitness Adaptations Following Eight Weeks of CrossFit ${ }^{\circledR}$. Int. J. Exerc. Sci. Conf. Proc. 2017, 2, 68.

6. Choi, E.-J.; So, W.-Y.; Jeong, T.T. Effects of the CrossFit Exercise Data Analysis on Body Composition and Blood Profiles. Iran. J. Public Health 2017, 46, 1292-1294. [PubMed]

7. Perna, S.; Bologna, C.; Degli Agosti, I.; Rondanelli, M. High Intensity Crossfit Training Compared to High Intensity Swimming: A Pre-Post Trial to Assess the Impact on Body Composition, Muscle Strength and Resting Energy Expenditure. Asian J. Sports Med. 2017, 9, 1-5. [CrossRef]

8. Drake, N.; Smeed, J.; Carper, M.J.; Crawford, A. Effects of Short-Term CrossFitTM Training: A Magnitude-Based Approach. J. Exerc. Physiol. 2017, 20, 111-133.

9. Escobar, K.A.; Morales, J.; VanDusseldorp, T.A. Metabolic profile of a crossfit training bout. J. Hum. Sport Exerc. 2017, 12, 1248-1255. [CrossRef]

10. Claudino, J.G.; Gabbett, T.J.; Bourgeois, F.; Souza, H.D.S.; Miranda, R.C.; Mezêncio, B.; Soncin, R.; Filho, C.A.C.; Bottaro, M.; Hernandez, A.J.; et al. CrossFit Overview: Systematic Review and Meta-analysis. Sports Med. Open 2018, 4, 11. [CrossRef]

11. Kliszczewicz, B.; John, Q.C.; Daniel, B.L.; Gretchen, O.D.; Michael, E.R.; Kyle, T.J. Acute Exercise and Oxidative Stress: CrossFit ${ }^{\mathrm{TM}}$ vs. Treadmill Bout. J. Hum. Kinet. 2015, 47, 81-90. [CrossRef] [PubMed]

12. Drum, S.N.; Bellovary, B.N.; Jensen, R.L.; Moore, M.M.T.; Donath, L. Perceived demands and post-exercise physical dysfunc-tion in CrossFit ${ }^{\circledR}$ compared to an ACSM based training session. J. Sports Med. Phys. Fit. 2017, 57, 604-609. [CrossRef]

13. Maté-Muñoz, J.L.; Lougedo, J.H.; Barba, M.; Cañuelo-Márquez, A.M.; Guodemar-Pérez, J.; García-Fernández, P.; Loza-no-Estevan, M.d.C.; Alonso-Melero, R.; Sánchez-Calabuig, M.A.; Ruíz-López, M.; et al. Cardiometabolic and muscular fa-tigue responses to different CrossFit ${ }^{\circledR}$ workouts. J. Sports Sci. Med. 2018, 17, 668-679.

14. Tibana, R.A.; De Almeida, L.M.; De Sousa, N.M.F.; Nascimento, D.D.C.; Neto, I.V.d.S.; De Almeida, J.A.; De Souza, V.C.; Lopes, M.d.F.T.P.L.; Nobrega, O.D.T.; Vieira, D.C.L.; et al. Two Consecutive Days of Extreme Conditioning Program Training Affects Pro and Anti-inflammatory Cytokines and Osteoprotegerin without Impairments in Muscle Power. Front. Physiol. $2016,7,260$. [CrossRef]

15. Maté-Muñoz, J.L.; Lougedo, J.H.; Barba, M.; García-Fernández, P.; Garnacho-Castaño, M.V.; Domínguez, R. Muscular fatigue in response to different modalities of CrossFit sessions. PLoS ONE 2017, 12, e0181855. [CrossRef] [PubMed]

16. Hak, P.T.; Hodzovic, E.; Hickey, B. The nature and prevalence of injury during CrossFit training. J. Strength Cond. Res. 2013. [CrossRef] [PubMed]

17. Weisenthal, B.M.; Beck, C.A.; Maloney, M.D.; DeHaven, K.E.; Giordano, B.D. Injury Rate and Patterns among CrossFit Athletes. Orthop. J. Sports Med. 2014, 2, 1-8. [CrossRef] [PubMed]

18. Keogh, J.W.L.; Winwood, P.W. The Epidemiology of Injuries Across the Weight-Training Sports. Sports Med. 2017, 47, 479-501. [CrossRef]

19. Hopkins, B.S.; Cloney, M.B.; Kesavabhotla, K.; Yamaguchi, J.; Smith, Z.A.; Koski, T.R.; Hsu, W.K.; Dahdaleh, N.S. Impact of CrossFit-Related Spinal Injuries. Clin. J. Sport Med. 2017, 29, 482-485. [CrossRef]

20. Hopkins, B.S.; Li, D.; Svet, M.; Kesavabhotla, K.; Dahdaleh, N.S. CrossFit and rhabdomyolysis: A case series of 11 patients presenting at a single academic institution. J. Sci. Med. Sport 2019, 22, 758-762. [CrossRef]

21. Butcher, S.J.; Neyedly, T.J.; Horvey, K.J.; Benko, C.R. Do physiological measures predict selected CrossFit ${ }^{\circledR b e n c h m a r k ~ p e r f o r-~}$ mance? Open Access J. Sports Med. 2015, 6, 241-247. [CrossRef]

22. Bellar, D.; Hatchett, A.; Judge, L.; Breaux, M.; Marcus, L. The relationship of aerobic capacity, anaerobic peak power and experience to performance in HIT exercise. Biol. Sport 2015, 32, 315-320. [CrossRef]

23. Zeitz, E.K.; Cook, L.F.; Dexheimer, J.D.; Lemez, S.; Leyva, W.D.; Terbio, I.Y.; Tran, J.R.; Jo, E. The Relationship between CrossFit ${ }^{\circledR}$ Performance and Laboratory-Based Measurements of Fitness. Sports 2020, 8, 112. [CrossRef] [PubMed]

24. Mangine, G.T.; Tankersley, J.E.; McDougle, J.M.; Velazquez, N.; Roberts, M.D.; Esmat, T.A.; VanDusseldorp, T.A.; Feito, Y. Predictors of CrossFit Open Performance. Sports 2020, 8, 102. [CrossRef] [PubMed]

25. Thomas, S.; Reading, J.; Shephard, R.J. Revision of the Physical Activity Readiness Questionnaire (PAR-Q). Can. J. Sport Sci. 1992, $17,338-345$.

26. World Medical Association. World Medical Association Declaration of Helsinki: Ethical principles for medical research involving human subjects. JAMA 2013, 310, 2191-2194. [CrossRef]

27. Jackson, A.S.; Pollock, M.L. Generalized equations for predicting body density of men. Br. J. Nutr. 1978, 40, 497-504. [CrossRef]

28. Häkkinen, K.; Kauhanen, H.; Komi, P.V. Biomechanical changes in the Olympic weightlifting technique of the Snatch and Clean \& Jerk from submaximal to maximal loads. Scand. J. Sports Sci. 1984, 6, 57-66.

29. Cronin, J.B.; McNair, P.J.; Marshall, R.N. Force-velocity analysis of strength-training techniques and load: Implications for training strategy and research. J. Strength Cond. Res. 2003, 17, 148. [CrossRef]

30. Bangsbo, J.; Iaia, F.M.; Krustrup, P. The Yo-Yo intermittent recovery test: A useful tool for evaluation of physical performance in intermittent sports. Sports Med. 2008, 38, 37-51. [CrossRef] 
31. Hopkins, W.G. A scale of magnitudes for effect statistics. Sportscience 2002, 5, 1-7.

32. Martínez-Gómez, R.; Valenzuela, P.L.; Barranco-Gil, D.; Moral-González, S.; García-González, A.; Lucia, A. Full-Squat as a Determinant of Performance in CrossFit. Int. J. Sports Med. 2019, 40, 592-596. [CrossRef]

33. Dexheimer, J.D.; Schroeder, E.T.; Sawyer, B.J.; Pettitt, R.W.; Aguinaldo, A.L.; Torrence, W.A. Physiological Performance Measures as Indicators of CrossFit ${ }^{\circledR}$ Performance. Sports 2019, 7, 93. [CrossRef] [PubMed]

34. Feito, Y.; Giardina, M.J.; Butcher, S.; Mangine, G.T. Repeated anaerobic tests predict performance among a group of advanced CrossFit-trained athletes. Appl. Physiol. Nutr. Metab. 2019, 44, 727-735. [CrossRef] [PubMed] 